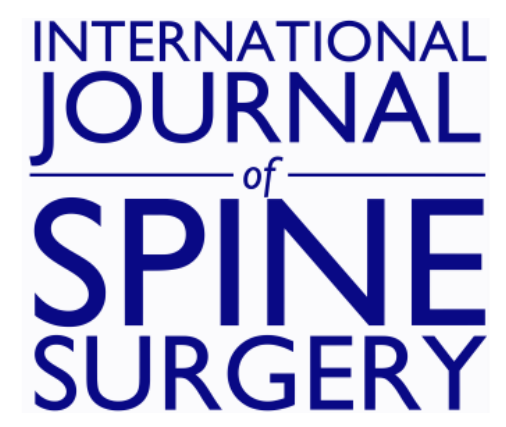

\title{
Observational Study of Depression in Patients Undergoing Cervical Disc Arthroplasty: Evidence of a Correlation between Pain Relief and Resolution of Depression
}

Matthew F. Gornet, Anne G. Copay, Francine W. Schranck and Branko Kopjar

Int J Spine Surg 2016, 10 ()

doi: https://doi.org/10.14444/3011

http://ijssurgery.com/content/10/11

This information is current as of April 26, 2023.

Email Alerts Receive free email-alerts when new articles cite this article. Sign up at:

http://ijssurgery.com/alerts

The International Journal of Spind Surgerhi 2397 Waterbury Circle, Suite 1, 


\section{Observational Study of Depression in Patients Undergoing Cervical Disc Arthroplasty: Evidence of a Correlation between Pain Relief and Resolution of Depression}

Matthew F. Gornet, MD,1 Anne G. Copay, PhD,2 Francine W. Schranck, BSN, 2 Branko Kopjar, MD, $M S, P h D^{3}$

${ }^{1}$ The Orthopedic Center of St. Louis, St Louis, MO, ${ }^{2}$ SPIRITT Research, St. Louis, MO, ${ }^{3}$ Department of Health Services, University of Washington, Seattle, $W A$

\section{Abstract}

\section{Background}

Depression has been associated with inferior outcomes following lumbar spine surgery. Our purpose was to investigate the prevalence of depression and its impact on the outcomes of a large sample of cervical disc arthroplasty patients and to examine the change in depression occurring in conjunction with changes in disability and pain.

\section{Methods}

A cohort of 271 patients who underwent single or multi-level cervical disc arthroplasty at a single orthopedic center filled out the Neck Disability Index, Medical Outcomes Study SF-36, numerical rating scales for neck pain and arm pain, preoperatively and 12-month postoperatively. Patients were classified as Depressed or Non-Depressed, based on their preoperative SF-36 Mental Component Summary (MCS) score. Preoperative scores, 12-month postoperative scores, and change in scores (adjusted for preoperative scores, smoking status, and strenuous job) were compared between Depressed and Non-Depressed. Next, patients in the 2 groups were subdivided into 4 groups: Always Depressed, Never Depressed, No Longer Depressed, and Newly Depressed, based on their combined preoperative and postoperative MCS scores. The same score comparisons were conducted among the 4 groups.

Results

Forty-four percent (118 of 271) of the patients in our sample were Depressed. Despite a significant improvement after surgery, Depressed patients had poorer pre- and postoperative scores than Non-Depressed patients for NDI, MCS, neck pain and arm pain. Two-thirds (80 of 118) of the Depressed patients were No Longer Depressed at 12 months and had postoperative scores similar to the Never Depressed patients. Eight percent (12 of 153) of the NonDepressed patients became Newly Depressed by 12 months and had postoperative scores similar to the Always Depressed patients.

\section{Conclusions}

Depression is a common occurrence in patients with cervical disorders. Relief from pain and disability after cervical disc arthroplasty can be associated with relief from depression, but poor outcomes may also result in patients becoming depressed.

KEYWORDS: DEPRESSION, PATIENT-REPORTED OUTCOMES, QUALITY OF LIFE, CERVICAL SPINE PATHOLOGY, CERVICAL DISC ARTHROPLASTY, SPINE SURGERY

VOLUME 10 ARTICLE 11 DOI: 10.14444/3011

\section{Introduction}

Depression is often the uninvited companion of chronic pain. According to the American Academy of Pain Medicine, 77\% of chronic pain sufferers report feeling depressed. ${ }^{1}$ Depression also often accompanies back pain; $46 \%$ of depressed individuals suffer from back pain or sciatica. ${ }^{2}$ The National Cen- ter for Health Statistics reports that adults with low back pain are more than 4 times as likely to experience serious psychological distress as people without low back pain. ${ }^{3}$ Furthermore, studies have shown that depressed patients obtain less pain relief from lumbar spine surgery than non-depressed patients. ${ }^{4-11}$ 
low back pain has been well-documented, less information is available about the relationship between depression and neck pain. One study found that, out of a group of 89 patients with cervical spondylotic myelopathy, more than a third suffered from depression or anxiety. ${ }^{12}$ As it does with lumbar surgery, depression also appears to diminish the benefits of cervical surgery. Preoperative depression, measured by the PHQ-9 (a self-administered patient questionnaire focusing on the symptoms of depression), predicted lower improvement on the EQ-5D (a standardized, self-assessment instrument used to measure health outcomes) after posterior cervical fusion. ${ }^{13}$ Similarly, the PHQ-9 scores in 61 cervical arthroplasty patients were associated with their 12-month postoperative outcomes, specifically, Neck Disability Index, Short Form-12, and pain scores. ${ }^{14}$ However, these studies did not examine the association between postoperative depression scores and disability or pain scores.

Our purpose was to investigate the prevalence of depression and its impact on the outcomes of a large sample of cervical disc arthroplasty patients. Secondarily, we examined the change in depression occurring in conjunction with changes in disability and pain.

\section{Material and Methods}

Sample

In this prospective, comparative, observational cohort study at a single large orthopedic center, consecutive patients aged 18 years and older who were undergoing cervical disc arthroplasty for symptomatic cervical disc conditions were prospectively enrolled and followed between December 2007 and March 2012. The study was approved by the institutional review board (IRB), and all patients gave their informed consent prior to enrollment.

\section{Patient-Reported Outcomes}

Patients were asked to answer the following standard questionnaires: the Neck Disability Index (NDI), ${ }^{15}$ numerical rating scales (0 to 10) for neck pain and arm pain ${ }^{16}$ and the Medical Outcomes Study Short Form-36-item questionnaire (SF-36). ${ }^{2}$ The patientreported outcomes (PRO) were collected preoperatively, and at 1.5, 3, 6, and 12 months, and annually thereafter. The change from preoperative scores to 12-month scores is the object of our analysis.

\section{Depression}

Typically, 2 summary scales are derived from the SF-36: the physical component summary (PCS) and the mental component summary (MCS). The MCS provides an indication of psychological well-being. Low MCS scores are indicative of depression. In the Medical Outcomes Study, individuals diagnosed with depression had an average MCS score of $34.84 .^{2}$ Another study used the Center for Epidemiologic Studies-Depression Scale (CES-D) to diagnose depression in patients and comparatively established that an MCS score of 35 was able to correctly identify $87 \%$ of the patients as depressed or not. ${ }^{17}$

In our study, patients with a preoperative MCS score below 35 were classified as Depressed and patients with a preoperative MCS score $\geq 35$ as NonDepressed.

The preoperative and 12-month MCS scores were considered jointly to further classify patients into 4 groups: Never Depressed (preoperative and 12-month MCS $\geq 35$ ), Always Depressed (preoperative and 12-month MCS < 35), Newly Depressed (preoperative MCS $\geq 35$ and 12-month MCS < 35), and No Longer Depressed (preoperative MCS $<35$ and 12-month MCS $\geq 35$ ).

\section{Socio-demographic data}

We collected the following preoperative sociodemographic data: age, gender, body mass index (BMI), smoking status, Workers' Compensation status, employment status, involvement in litigation, performance of physically demanding work, and educational level.

\section{Medical data}

We recorded co-morbidities, diagnoses, number of arthroplasty levels, and complications and reoperations.

\section{Analyses}

Preoperative sociodemographic characteristics, scores from patient-reported outcomes, and medical data were compared between the Depressed and Non- 
Depressed groups using the Student $t$ test for continuous data and using the chi-square test for categorical data. Repeated-measures analysis of variance was used to assess the patient-reported outcomes from preoperative to 1 year. We compared the change in preoperative score between the Depressed and NonDepressed patients at 1 year with analysis of covariance, adjusting for preoperative scores, smoking status and strenuous job. The same analyses were carried out for the 4 patients groups. Statistical analyses were performed with SPSS (version 22, SPSS Inc., Chicago, IL).

\section{Results}

\section{Prevalence of depression}

Of the 271 patients with 12-month follow-up data, 118 (44\%) had an MCS score below 35 and were classified as Depressed. Preoperative and surgical characteristics are reported in Table 1. Depressed patients were more likely to be smokers and to have physically demanding jobs than Non-Depressed patients. Depressed patients also reported higher preoperative disability, neck pain, and arm pain than Non-Depressed patients (Table 2).

\section{Effects of depression on outcomes}

Except for PCS scores, Depressed patients had worse outcome scores both preoperatively and at 12 months after surgery. They had higher disability, higher neck pain, higher arm pain, and lower MCS scores at 12 months than Non-Depressed patients (Table 2). However, both Depressed and Non-Depressed patients achieved statistically significant improvement on all scores at 12 months. Furthermore, Depressed patients improved more than Non-Depressed patients in NDI and MCS scores, but less in PCS scores (Table 2 and Figure 1).

After adjusting for preoperative scores, smoking status, and strenuous work (these preoperative variables were significantly different between the 2 groups), the change in outcome scores remained statistically different between Depressed and Non-Depressed patients (Table 3). Notably, Depressed patients had greater improvement in disability, depression, and neck pain than Non-Depressed patients. Despite this greater improvement, their 12-month scores indicat- ed that Depressed patients experienced greater disability, pain, and depression 12 months postoperatively (Table 2).

\section{Effect of outcomes on depression}

Table 4 shows the preoperative and 12-month scores for the Never Depressed ( $\mathrm{n}=140)$, Always Depressed $(\mathrm{n}=39)$, No Longer Depressed $(\mathrm{n}=80)$, and Newly Depressed $(\mathrm{n}=12)$ groups. The improvement is statistically significant for all groups but different between

\begin{tabular}{|c|c|c|c|}
\hline Characteristic/Variable & $\begin{array}{c}\text { Depressed } \\
\mathrm{n}=118\end{array}$ & $\begin{array}{l}\text { Non-Depressed } \\
\qquad \mathbf{n}=153\end{array}$ & p-value \\
\hline Age (years) & $45.7(9.2)$ & $45.5(8.7)$ & .876 \\
\hline Body mass index $\left(\mathrm{kg} / \mathrm{m}^{2}\right)$ & $28.8(5.4)$ & $28.8(6.0)$ & .984 \\
\hline Time to treatment (days) ${ }^{*}$ & $391.0(286.5)$ & $412.7(372.9)$ & .614 \\
\hline Male gender & $69(58.5 \%)$ & $85(55.9 \%)$ & .674 \\
\hline Smoker & $65(55.1 \%)$ & $61(40.1 \%)$ & .015 \\
\hline Workers' Compensation & $86(72.9 \%)$ & $108(71.1 \%)$ & .740 \\
\hline Litigation & $83(70.3 \%)$ & $93(61.2 \%)$ & .117 \\
\hline Strenuous job & $90(78.3 \%)$ & $93(63.7 \%)$ & .011 \\
\hline Currently employed & $108(91.5 \%)$ & $138(92.0 \%)$ & .888 \\
\hline \multicolumn{4}{|l|}{ Education } \\
\hline Less than high school & $12(10.7 \%)$ & $26(18.2 \%)$ & \multirow{5}{*}{.515} \\
\hline High school & $54(48.2 \%)$ & $68(47.6 \%)$ & \\
\hline Associate degree & $24(21.4 \%)$ & $25(17.5 \%)$ & \\
\hline College & $13(11.6 \%)$ & $13(9.1 \%)$ & \\
\hline Master/Professional & $9(8.0 \%)$ & $11(7.7 \%)$ & \\
\hline \multicolumn{4}{|l|}{ Diagnosis } \\
\hline Discogenic pain & $50(42.4 \%)$ & $63(41.4 \%)$ & \multirow{3}{*}{.238} \\
\hline Herniated disc & $37(31.4 \%)$ & $61(40.1 \%)$ & \\
\hline Radiculopathy & $30(25.4 \%)$ & $28(18.4 \%)$ & \\
\hline \multicolumn{4}{|l|}{ Number of comorbidities } \\
\hline None & $81(68.6 \%)$ & $108(71.1 \%)$ & \multirow{4}{*}{.583} \\
\hline 1 comorbidity & $27(22.9 \%)$ & $36(23.7 \%)$ & \\
\hline 2 comorbidities & $9(7.6 \%)$ & $8(5.3 \%)$ & \\
\hline 3 comorbidities & $1(0.4 \%)$ & 0 & \\
\hline Number of re-operations & $4(3.4 \%)$ & $6(3.9 \%)$ & .810 \\
\hline Number of AEs & $8(6.8 \%)$ & $5(3.3 \%)$ & .407 \\
\hline \multicolumn{4}{|l|}{ Number of operated levels } \\
\hline 1 level & $60(50.8 \%)$ & $82(53.9 \%)$ & \multirow{3}{*}{.136} \\
\hline 2 levels & $45(38.1 \%)$ & $63(41.4 \%)$ & \\
\hline 3 levels & $13(11.0 \%)$ & $7(4.6 \%)$ & \\
\hline
\end{tabular}


groups. The rate of improvement differs between groups for NDI and PCS.

Figure 2 depicts the preoperative to 12 -month improvement of the 4 groups. The No Longer Depressed group exhibited the sharpest decline in neck disability. At 12 months, the disability level of the No Longer Depressed and Never Depressed patients was much lower than that of the Newly Depressed and Always Depressed patients. The Never Depressed patient group reported the greatest improvement in general health as indicated by their PCS scores. At 12 months, the general health level of the Never Depressed and No Longer Depressed patients was higher than the 2 other patient groups. Neck pain and arm pain decreased at a similar rate for the 4 groups.

Table 2. Preoperative and 12-month postoperative Patient-Reported Outcomes: mean (standard deviation).

\begin{tabular}{|c|c|c|c|c|c|c|c|c|c|c|}
\hline \multirow[t]{2}{*}{ Group } & \multicolumn{2}{|c|}{ NDI } & \multicolumn{2}{|c|}{ PCS } & \multicolumn{2}{|c|}{ MCS } & \multicolumn{2}{|c|}{ Neck Pain } & \multicolumn{2}{|c|}{ Arm Pain } \\
\hline & Preop & $12 \mathrm{mo}$ & Preop & $12 \mathrm{mo}$ & Preop & $12 \mathrm{mo}$ & Preop & $12 \mathrm{mo}$ & Preop & $12 \mathrm{mo}$ \\
\hline Depressed & $62.4(15.1)$ & $31.6(21.1)$ & $35.5(6.6)$ & $42.5(11.4)$ & $27.0(5.6)$ & $41.9(12.0)$ & $7.6(1.6)$ & $3.3(2.5)$ & $5.8(2.8)$ & $3.0(2.7)$ \\
\hline Non-Depressed & $48.5(15.1)$ & $22.8(18.3)$ & $33.7(6.7)$ & $45.1(10.2)$ & $46.6(8.2)$ & $51.3(10.5)$ & $6.6(2.0)$ & $2.7(2.4)$ & $4.8(2.8)$ & $1.8(2.4)$ \\
\hline $\mathrm{P}^{*}$ & \multicolumn{2}{|c|}{$<.001$} & \multicolumn{2}{|c|}{.688} & \multicolumn{2}{|c|}{$<.001$} & \multicolumn{2}{|c|}{$<.001$} & \multicolumn{2}{|c|}{$<.001$} \\
\hline $\mathrm{P} \dagger$ & \multicolumn{2}{|c|}{$<.001$} & \multicolumn{2}{|c|}{$<.001$} & \multicolumn{2}{|c|}{$<.001$} & \multicolumn{2}{|c|}{$<.001$} & \multicolumn{2}{|c|}{$<.001$} \\
\hline $\mathrm{P}$ & \multicolumn{2}{|c|}{.050} & \multicolumn{2}{|c|}{$<.001$} & \multicolumn{2}{|c|}{$<.001$} & \multicolumn{2}{|c|}{.251} & \multicolumn{2}{|c|}{.755} \\
\hline
\end{tabular}

NDI, Neck Disability Index; PCS, Physical Component Summary of the SF-36; MCS, Mental Component Summary of the SF-36. *Probability for difference between Depressed and Non-Depressed patients. † Probability for difference from preoperative to 12-month postoperative. $\neq$ Probability for interaction between depression status and change preoperative to 12-month.

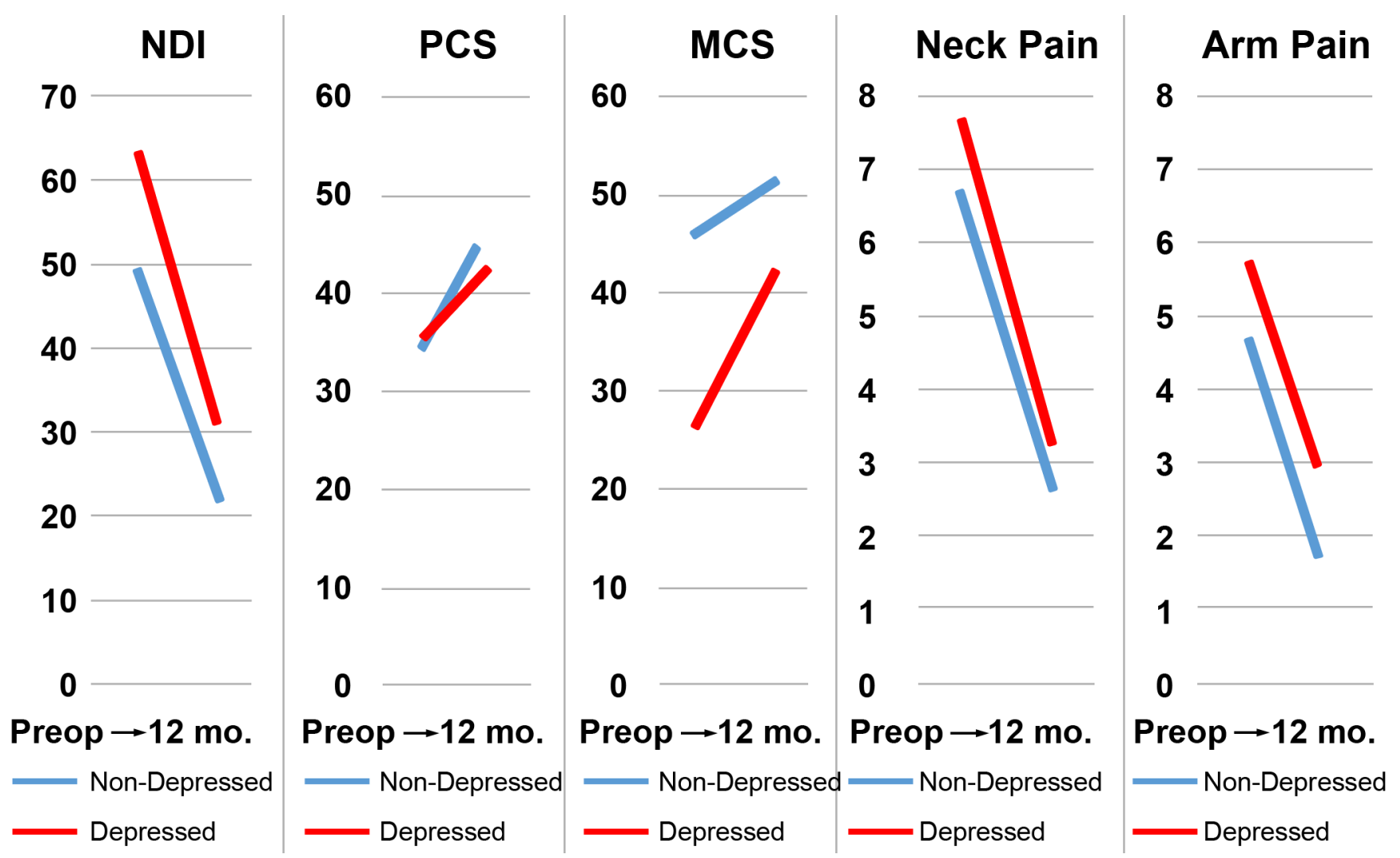

Fig. 1. Preoperative and 12-month scores of Depressed and Non-Depressed patients for NDI, PCS, MCS, neck pain, and arm pain. NDI: neck disability index (lower scores indicate improvement); PCS: physical component summary of the SF-36; MCS: mental component summary of the SF-36 (higher scores indicate improvement). 
However, due to higher preoperative pain levels, the 12-month pain levels differed among some groups. Notably, the Never Depressed and No Longer Depressed patient groups had the lowest pain levels at 12 months.

Table 5 reports the preoperative to 12 -month change in scores for the 4 groups, adjusted for preoperative scores, smoking status, and strenuous work. The change in all scores is significantly different among the 4 groups; however, the change in MCS is due to the definition of the 4 groups. The No Longer Depressed had the greatest improvement in NDI, neck pain, and arm pain. On the contrary, the Nemly Depressed patients had the smallest improvement in $\mathrm{NDI}$, neck pain, and arm pain.

\section{Discussion}

A large proportion of individuals who have neck pain are depressed. We found that $44 \%$ of the patients in our sample were depressed; this proportion is in line with the proportions of depression reported for pa- tients suffering from low back pain. ${ }^{9,18-20} \mathrm{We}$ also found that depressed patients reported higher levels of disability and pain. It is our contention that it is just as likely that depression results from higher levels of pain and disability rather than depression heightening pain and disability.

All patients, Depressed and Non-Depressed alike, were significantly improved at 12 months after surgery. However, the 12-month outcomes of the Depressed patients were poorer than those of the Non-Depressed patients. At 12 months after surgery, the Depressed patients had higher NDI, neck pain, and arm pain scores than Non-Depressed patients. This situation is similar to that of lumbar spine surgical patients, in whom it has been found that patients suffering from depression preoperatively will have diminished improvement in their patient-reported outcomes after surgery. ${ }^{4-11}$

However, we also demonstrated that one should not conclude that depression hinders the recovery from cervical spine surgery. In our sample, $68 \%$ of the pa-

Table 3. Change in preoperative Patient-Reported Outcomes at 12 months: mean (SD).

\begin{tabular}{|l|c|c|c|}
\hline Outcomes & Depressed & Non-Depressed & P $^{*}$ \\
\hline NDI & $30.6(22.0)$ & $25.7(20.0)$ & $<.001$ \\
\hline PCS & $7.0(9.5)$ & $11.3(10.1)$ & .002 \\
\hline MCS & $14.9(12.4)$ & $4.7(11.4)$ & $<.001$ \\
\hline Neck pain & $4.3(2.8)$ & $3.9(2.9)$ & $<.001$ \\
\hline Arm pain & $2.8(3.2)$ & $2.9(3.1)$ & $<.001$ \\
\hline
\end{tabular}

NDI, Neck Disability Index; PCS, Physical Component Summary; MCS, Mental Component Summary. *Adjusted for preoperative scores, smoking status, and strenuous work.

Table 4. Preoperative and 12-month postoperative Patient-Reported Outcomes: mean (standard deviation).

\begin{tabular}{|c|c|c|c|c|c|c|c|c|c|c|}
\hline \multirow[t]{2}{*}{ Group } & \multicolumn{2}{|c|}{ NDI } & \multicolumn{2}{|c|}{ PCS } & \multicolumn{2}{|c|}{ MCS } & \multicolumn{2}{|c|}{ Neck Pain } & \multicolumn{2}{|c|}{ Arm Pain } \\
\hline & Preop & $12 \mathrm{mo}$ & Preop & $12 \mathrm{mo}$ & Preop & $12 \mathrm{mo}$ & Preop & $12 \mathrm{mo}$ & Preop & $12 \mathrm{mo}$ \\
\hline Never Depressed & $47.2(14.6)$ & $20.6(16.8)$ & $34.1(6.8)$ & $45.9(10.2)$ & $47.2(8.2)$ & $53.4(8.1)$ & $6.5(2.0)$ & $2.5(2.3)$ & $4.8(2.8)$ & $1.7(2.3)$ \\
\hline Always Depressed & $66.2(13.7)$ & $42.9(17.2)$ & $33.5(5.5)$ & $38.5(9.2)$ & $26.0(6.1)$ & $28.5(5.1)$ & $7.6(1.4)$ & $4.0(2.5)$ & $5.9(2.8)$ & $3.5(2.8)$ \\
\hline Newly Depressed & $64.0(12.4)$ & $47.8(15.6)$ & $28.9(3.3)$ & $35.7(4.9)$ & $39.7(5.3)$ & $27.8(5.9)$ & $7.3(1.8)$ & $4.3(2.4)$ & $5.4(2.9)$ & $3.1(3.0)$ \\
\hline No Longer Depressed & $60.2(15.5)$ & $26.3(20.6)$ & $36.5(6.9)$ & $44.5(11.9)$ & $27.5(5.3)$ & $48.6(8.3)$ & $7.6(1.7)$ & $2.9(2.4)$ & $5.8(2.8)$ & $2.8(2.6)$ \\
\hline $\mathrm{P}^{*}$ & \multicolumn{2}{|c|}{$<.001$} & \multicolumn{2}{|c|}{$<.001$} & \multicolumn{2}{|c|}{$<.001$} & \multicolumn{2}{|c|}{$<.001$} & \multicolumn{2}{|c|}{$<.001$} \\
\hline $\mathrm{P} \dagger$ & \multicolumn{2}{|c|}{$<.001$} & \multicolumn{2}{|c|}{$<.001$} & \multicolumn{2}{|c|}{$<.001$} & \multicolumn{2}{|c|}{$<.001$} & \multicolumn{2}{|c|}{$<.001$} \\
\hline Pł & \multicolumn{2}{|c|}{.005} & \multicolumn{2}{|c|}{$<.001$} & \multicolumn{2}{|c|}{$<.001$} & \multicolumn{2}{|c|}{.120} & \multicolumn{2}{|c|}{.613} \\
\hline
\end{tabular}

NDI, Neck Disability Index; PCS, Physical Component Summary; MCS, Mental Component Summary. *Probability for difference between depression groups. † Probability for difference from preoperative to 1-year postoperative. ₹ Probability for interaction between depression status and change from preoperative to 1 year. 
tients who were depressed preoperatively were no longer depressed at 12 months; those patients reported the greatest improvement in pain and disability. On the other hand, $8 \%$ of the patients who were not depressed preoperatively had become depressed by 12 months after surgery. Those patients reported the smallest improvement in disability and pain. Given that depression seems to be erased by good outcomes and spurred by poor outcomes, it seems logical to assume that outcomes are responsible for depressive states after surgery and not the other way around. This possibility has already been suggested for lumbar spine patients. ${ }^{20,21}$

Thirty-three percent of depressed patients in our study remained depressed at 12 months. Their out-

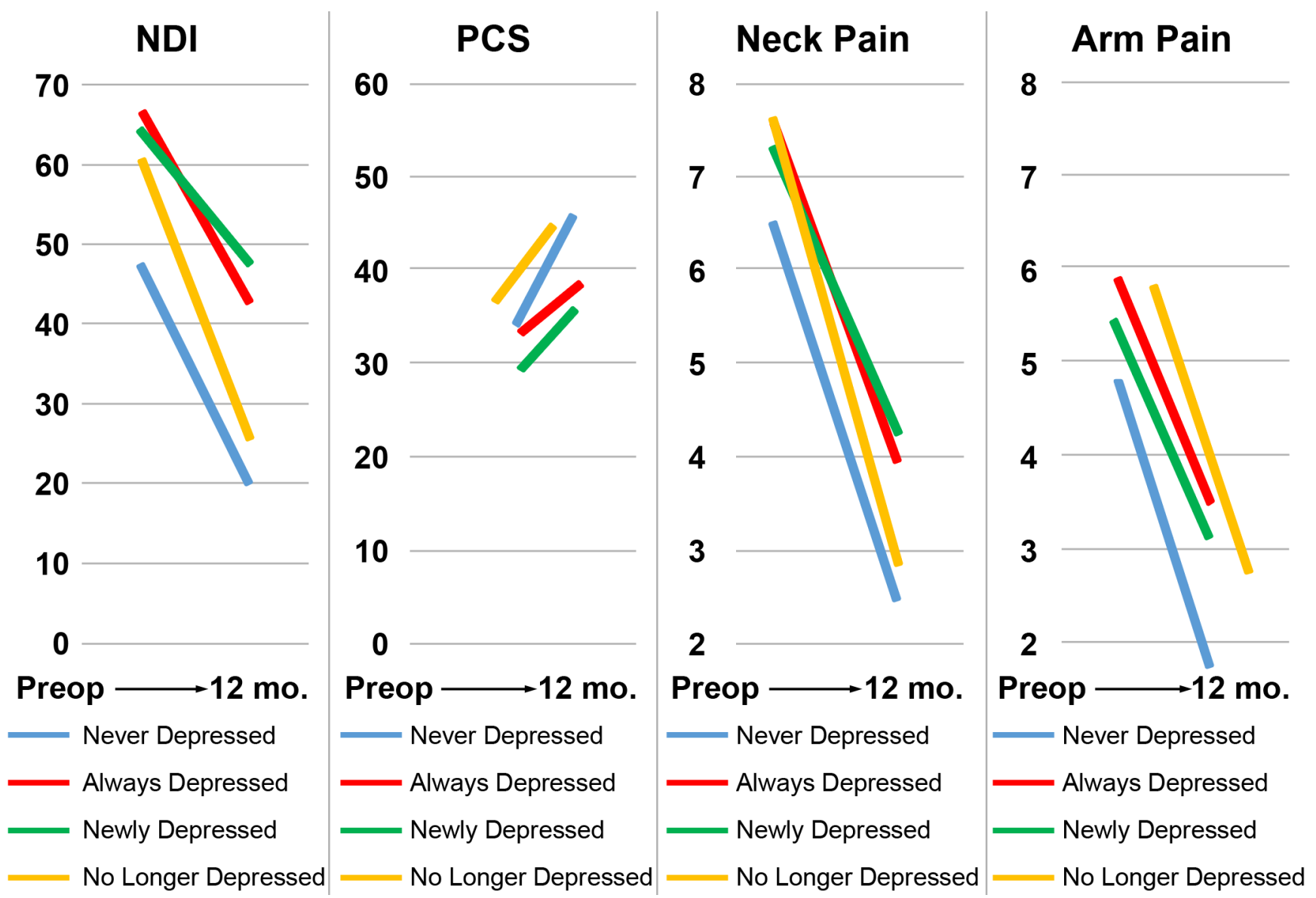

Fig. 2. Preoperative and 12-month scores by depression status for NDI, PCS, neck pain, and arm pain. NDI: neck disability index (lower scores indicate improvement); PCS: physical component summary of the SF-36; MCS: mental component summary of the SF-36 (higher scores indicate improvement).

Table 5. Change in Patient-Reported Outcomes from preoperative to 12 months: mean (SD).

\begin{tabular}{|l|c|c|c|c|}
\hline Outcomes & Never Depressed & Always Depressed & Newly Depressed & No Longer Depressed \\
\hline NDI & $26.2(20.2)$ & $23.3(19.0)$ & $16.2(17.9)$ & $34.6(22.9)$ \\
\hline PCS & $11.5(10.3)$ & $4.8(7.0)$ & $6.8(4.6)$ & $<.1(10.6)$ \\
\hline MCS & $6.2(10.6)$ & $2.5(5.7)$ & $-12.0(8.5)$ & $21.3(9.9)$ \\
\hline Neck pain & $4.0(2.9)$ & $3.6(2.8)$ & $2.9(2.8)$ & $<.6(2.9)$ \\
\hline Arm pain & $3.0(3.1)$ & $2.5(3.1)$ & $2.3(2.5)$ & $3.1(3.2)$ \\
\hline
\end{tabular}

NDI, Neck Disability Index; PCS, Physical Component Summary; MCS, Mental Component Summary. *Adjusted for preoperative scores, smoking status, and strenuous work. 
comes were similar to those of the Nemly Depressed patients. It is not possible to definitively say whether the persistence of the depression was due to the mediocre outcomes, or whether the depression caused the mediocre outcomes. It is possible that both situations exist in this group of patients.

It has been suggested that depressed patients should not be candidates for spinal fusion or, at the least, should be treated for their depression prior to surgery. ${ }^{11}$ We are aware of a patient without prior history of mental disorders who was required to undergo a full psychological evaluation to obtain health insurance authorization for spine surgery. Our results indicate that the widely held belief that depression causes poorer surgical outcomes should be reconsidered. In particular, further study should be conducted to investigate the association between depression and outcomes of spine surgery.

A limitation of our study resides in its definition of depression based on a single questionnaire score. A rigorous diagnosis of depression would require an extensive evaluation of the patient. Nevertheless, spine surgery studies have traditionally relied on a single indicator of depression or psychological state, such as MCS. ${ }^{5,22}$ We relied on the MCS score as an index of depression for three reasons. First, the MCS score has been shown to be related with other measures of depression and to be a valid measure of depression. ${ }^{2,17,23-25}$ Second, MCS is part of the SF-36 questionnaire that is widely used in clinical assessment and, thus, available for a large number of patients. Third, and most importantly, many studies of spine surgeries have specifically included MCS as a predictor of surgery outcomes and have concluded that a low MCS score is a predictor of poor outcomes. ${ }^{6,11,22}$ $\mathrm{We}$, thus, felt that it was important to further investigate the association between MCS and surgery outcomes.

Another limitation of our study stems from the fact that the outcomes of spine surgery are influenced by the sociodemographic characteristics of the patients. Given that our study is a nonrandomized observational cohort study, our results may be influenced by the specific characteristics of our patient sample. Depressed patients in our sample were more likely to be smokers and to have physically demanding jobs, characteristics reported to influence surgical outcomes. Patients who suffer from depression in other populations may have different characteristics with varying impact on surgical outcomes. However, there were no statistical differences in the 12-month change in any of the patient-reported outcomes between patients with and without physically demanding jobs, in our sample (data not reported). The 12-month change in NDI (but not the other patientreported outcomes) was significantly different between smokers and non-smokers (30.76 and 25.19 NDI points, respectively; $\mathrm{p}=0.029)$. As described in Table 6, depression, but not smoking, was associated with higher pre-operative NDI scores while depressed smokers had the highest 12-month NDI improvement. Hence, the influence of depression on NDI may outweigh the influence of other sociodemographic characteristics.

Also, our sample was constituted of arthroplasty patients and it is possible that the reported outcomes may have been influenced by the patients' perception of arthroplasty as a state-of-art treatment, as opposed to fusion, the standard of care. However, it has been found elsewhere that relief of pain and disability was positively correlated with relief of depression after lumbar fusion. ${ }^{20}$ Hence, the lifting of depression concomitant with pain relief is not exclusive to arthroplasty.

\section{Conclusion}

Neck pain invites depression, a condition that it shares with low back pain and other chronic pain syndromes. Depression, pain, and disability are interrelated and depression does not necessarily impair improvements from spine surgery. When a depressed patient is a candidate for cervical spine surgery, the decision for surgical treatment should not be based on a preoperative diagnosis of depression.

\section{References}

1. American Society of Anesthesiologists Task

Force on Chronic Pain Management, American Society of Regional Anesthesia and Pain Medicine. Prac- 
tice guidelines for chronic pain management: an updated report by the American Society of Anesthesiologists Task Force on Chronic Pain Management and the American Society of Regional Anesthesia and Pain Medicine. Anesthesiology 2010;112:810-33.

2. Ware JE, Kosinski M, Keller SK. SF-36 Physical and Mental Health Summary Scales: A User's Manualed. Boston, MA: The Health Institute, 1994.

3. National Center for Health Statistics. Health, United States, 2006. With Chartbook on Trends in the Health of Americains. In U.S. Department of Health and Human Services ed. Hyattsville, MD: U.S. Government Printing Office, 2006.

4. Miller JA, Derakhshan A, Lubelski D, et al. The impact of preoperative depression on quality of life outcomes after lumbar surgery. Spine $J$ 2015;15:58-64.

5. Derby R, Lettice JJ, Kula TA, et al. Single-Level Lumbar Fusion in Chronic Discogenic Low-Back Pain: Psychological and Emotional Status as a predictor of Outcome Measured Using the 36-Item ShortForm. Journal of Neurosurgery: Spine 2005;3:255-61. 6. LaCaille RA, DeBerard MS, Masters KS, et al. Presurgical biopsychosocial factors predict multidimensional patient: outcomes of interbody cage lumbar fusion. Spine J 2005;5:71-8.

7. Adogwa O, Parker SL, Shau DN, et al. Preoperative Zung depression scale predicts patient satisfaction independent of the extent of improvement after revision lumbar surgery. Spine J 2013;13:501-6.

8. Sinikallio S, Aalto T, Airaksinen O, et al. Depression is associated with poorer outcome of lumbar spinal stenosis surgery. Eur Spine J 2007;16:905-12. 9. Urban-Baeza A, Zarate-Kalfopulos B, RomeroVargas $S$, et al. Influence of depression symptoms on patient expectations and clinical outcomes in the surgical management of spinal stenosis. J Neurosurg Spine 2015;22:75-9.
10. Trief PM, Grant W, Fredrickson B. A prospective study of psychological predictors of lumbar surgery outcome. Spine (Phila Pa 1976) 2000;25:2616-21.

11. Trief PM, Ploutz-Snyder R, Fredrickson BE. Emotional health predicts pain and function after fusion: a prospective multicenter study. Spine (Phila Pa 1976) 2006;31:823-30.

12. Stoffman MR, Roberts MS, King JT, Jr. Cervical spondylotic myelopathy, depression, and anxiety: a cohort analysis of 89 patients. Neurosurgery 2005;57:307-13; discussion -13.

13. Alvin MD, Miller JA, Sundar S, et al. The impact of preoperative depression on quality of life outcomes after posterior cervical fusion. Spine $J$ 2015;15:79-85.

14. He J, Xiong W, Li F, et al. Depression influences pain and function after cervical disc arthroplasty. Journal of neurosurgical sciences 2014.

15. Vernon H, Mior S. The Neck Disability Index: a study of reliability and validity. Journal of manipulative and physiological therapeutics 1991;14:409-15. 16. McDowell I, Newell C. Measuring Health. A Guide to Rating Scales and Questionnairesed. New York: Oxford University Press, 1996.

17. Walsh TL, Homa K, Hanscom B, et al. Screening for depressive symptoms in patients with chronic spinal pain using the SF-36 Health Survey. Spine $J$ 2006;6:316-20.

18. Lubelski D, Thompson NR, Bansal S, et al. Depression as a predictor of worse quality of life outcomes following nonoperative treatment for lumbar stenosis. J Neurosurg Spine 2015;22:267-72.

19. Atkinson JH, Slater MA, Patterson TL, et al. Prevalence, onset, and risk of psychiatric disorders in men with chronic low back pain: a controlled study. Pain 1991;45:111-21.

20. Wahlman M, Hakkinen A, Dekker J, et al. The

Table 6. NDI Change from preoperative to 12 months: mean (SD).

\begin{tabular}{|c|c|c|c|c|c|}
\hline NDI & $\begin{array}{l}\text { Non Depressed Non Smoker } \\
\qquad \mathrm{N}=91\end{array}$ & $\begin{array}{c}\text { Non Depressed Smoker } \\
\qquad \mathrm{N}=61\end{array}$ & $\begin{array}{c}\text { Depressed Non Smoker } \\
\qquad \mathbf{N}=55\end{array}$ & $\begin{array}{l}\text { Depressed Smoker } \\
\qquad N=65\end{array}$ & $\mathbf{P}^{*}$ \\
\hline Pre-Op & $47.8(15.6)$ & $49.5(14.4)$ & $60.8(16.0)$ & $63.3(14.3)$ & $<.001$ \\
\hline 12-month & $22.8(18.8)$ & $22.7(17.6)$ & $35.3(21.5)$ & $28.8(20.3)$ & .001 \\
\hline Change & $25.0(20.6)$ & $26.8(19.1)$ & $25.5(19.9)$ & $34.5(23.1)$ & .029 \\
\hline
\end{tabular}


prevalence of depressive symptoms before and after surgery and its association with disability in patients undergoing lumbar spinal fusion. Eur Spine $J$ 2014;23:129-34.

21. Havakeshian S, Mannion AF. Negative beliefs and psychological disturbance in spine surgery patients: a cause or consequence of a poor treatment outcome? Eur Spine J 2013;22:2827-35.

22. Carreon LY, Glassman SD, Djurasovic M, et al. Are preoperative health-related quality of life scores predictive of clinical outcomes after lumbar fusion? Spine (Phila Pa 1976) 2009;34:725-30.

23. Gill SC, Butterworth P, Rodgers B, et al. Validity of the mental health component scale of the 12-item Short-Form Health Survey (MCS-12) as measure of common mental disorders in the general population. Psychiatry Res 2007;152:63-71.

24. Silveira E, Taft C, Sundh V, et al. Performance of the SF-36 health survey in screening for depressive and anxiety disorders in an elderly female Swedish population. Qual Life Res 2005;14:1263-74. 25. Yu DS, Yan EC, Chow CK. Interpreting SF-12 mental component score: an investigation of its convergent validity with CESD-10. Qual Life Res
2015;24:2209-17.

\section{Disclosures \& COI}

Dr. Copay has nothing to disclose. Dr. Gornet reports owning stock from Bonovo, consultancy from K2M, grants, research support, and consultancy from Medtronic, stock from Ouroborus, stock from Paradigm Spine, stock from International Spine and Orthopedic Institute, and stock from Nocimed, outside the submitted work. Dr. Kopjar has nothing to disclose. Ms. Schranck has nothing to disclose.

\section{Corresponding Author}

Matthew F. Gornet, MD, The Orthopedic Center of St. Louis, 14825 N. Outer Forty Road, Suite 200, St Louis, MO 63141.mfgspine@gmail.com.

Published 1 April 2016.

This manuscript is generously published free of charge by ISASS, the International Society for the Advancement of Spine Surgery. Copyright $\odot 2016$ ISASS. To see more or order reprints or permissions, see http://ijssurgery.com. 